\title{
ASO Visual Abstract: Extended Right Hepatectomy for Hepatocellular Carcinoma
}

\author{
F. Crafa, MD, S. Vanella, MD (i) , E. Coppola Bottazzi, MD, A. Noviello, MD, A. Miro, MD, \\ T. Palma, MD, and I. Apicella, MD
}

General and Oncological Surgery Unit, Hospital of National Relevance and High Specialty "St. Giuseppe Moscati", Avellino, Italy

In their video article (https://doi.org/10.1245/s10434-0 21-10567-0), the authors present their approach to a large liver tumor in close contact with the vena cava and the hepatocaval confluence. In difficult cases, a thoracoabdominal approach allows safer control of the liver, inferior vena cava, and hepatocaval confluence.

Supplementary Information The online version contains supplementary material available at https://doi.org/10.1245/s10434021-10675-x.

(C) Society of Surgical Oncology 2021

Published Online: 25 August 2021

F. Crafa, MD

e-mail: crafa@tiscali.it
AUTHOR CONTRIBUTIONS All authors have seen and approved the manuscript submitted for publication. They warrant that the article is the authors' original work and that the article is not under consideration for publication elsewhere or has not been previously published. On behalf of all co-authors, the corresponding author bears full responsibility for the submission.

DISCLOSURES F. Crafa, S. Vanella, E. Coppola Bottazzi, A. Noviello, A. Miro, T. Palma, and I. Apicella have no conflicts of interest, commercial interests, or financial or material support to declare in relation to this Visual Abstract.

Publisher's Note Springer Nature remains neutral with regard to jurisdictional claims in published maps and institutional affiliations. 